\title{
CORRIGENDUM
}

\section{HAND1 gene expression is negatively regulated by the High Mobility Group A1 proteins and is drastically reduced in human thyroid carcinomas}

JM Hoyos, A Ferraro, S Sacchetti, S Keller, I De Martino, E Borbone, P Pallante, M Fedele, D Montanaro, F Esposito, P Cserjesi, L Chiariotti, G Troncone and A Fusco

Oncogene (2016) 35, 5930; doi:10.1038/onc.2016.137; published online 27 June 2016

Correction to: Oncogene (2009) 28, 876-885; doi:10.1038/ onc. 2008.438

Shown are raw images from a replicate experiment in support of the results shown in the Figure 1a of this article. Readers will note that these results confirm those shown in Figure 1a of the published article. Indeed, the HAND1 gene mRNA is virtually absent in the wild-type ES +/+ cells, while it is clearly detected in the ES HMGA1 +/ - (roughly 50\%dosage) and in the ES HMGA1 - / (null) cells. In contrast, HAND2 gene mRNA does not show any

$$
\begin{aligned}
& +\frac{1}{+} \frac{1}{4} \\
& \text { 品尔 }
\end{aligned}
$$

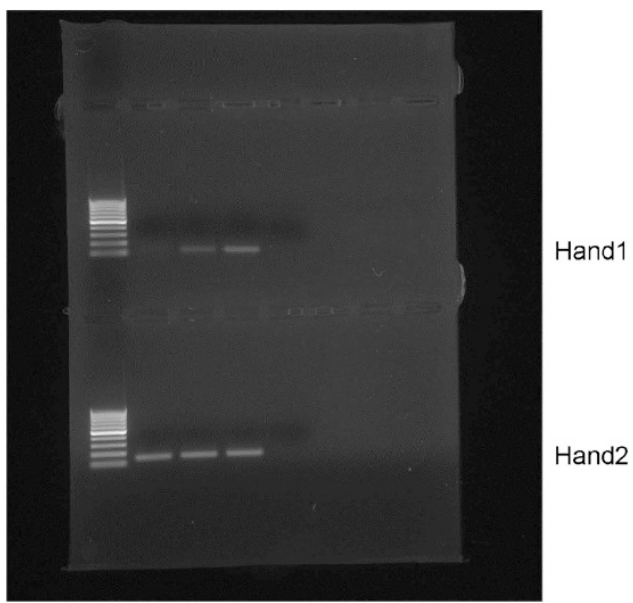

Figure 1. Top panel: RT-PCR analysis of HAND1 gene expression in HMGA $1+/+,+/-$ and $-/-$ ES cells. The lanes have been loaded from left to right: ES cells +/+, ES cells +/-, ES cells -/-. No RNA $\left(\mathrm{H}_{2} \mathrm{O}\right.$, reported as negative control). Bottom panel: RT-PCR analysis of HAND2 gene expression. The samples have been loaded in the same order as in the top panel. difference in its expression levels among the three cell types (Figure 1).

As a control, Figure 2 shows the expression of HMGA1 specific mRNA in the same three cell types: as expected, HMGA1 mRNA is present in the wild-type ES +/+ cells, is completely absent in ES HMGA1 null cells and is reduced to $50 \%$ in ES HMGA1 +/ - cells. As a control, beta-actin expression levels are reported for normalization.

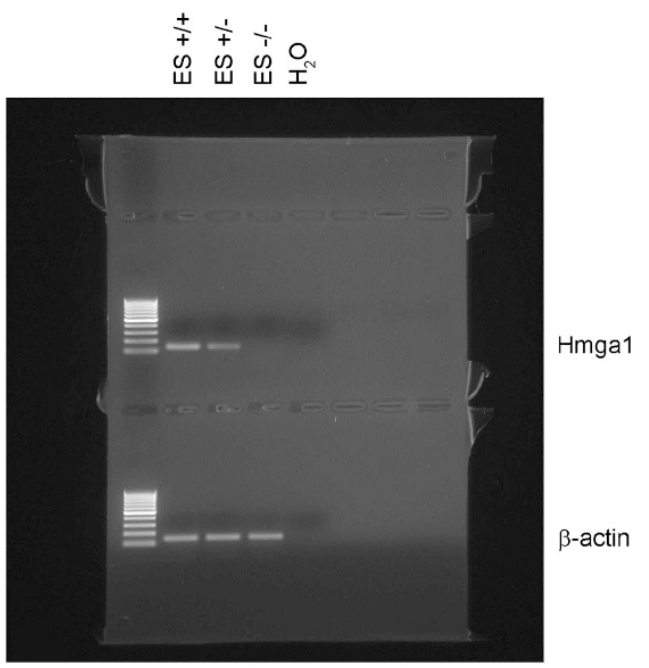

Figure 2. Top panel: RT-PCR analysis of HMGA1 expression in HMGA $1+/+,+/-$ and $-/-$ ES cells. The lanes have been loaded from left to right: ES cells $+/+$, ES cells $+/-$, ES cells $-/-$. No RNA $\left(\mathrm{H}_{2} \mathrm{O}\right.$, reported as negative control). Bottom panel: RT-PCR analysis of beta-actin expression. The samples have been loaded in the same order as in the top panel. 